\title{
A EDUCAÇÃO EM SAÚDE E A BNCC EM TEMPOS DE PANDEMIA
}

Roberto Tadeu laochite ${ }^{1}$ http://orcid.org/0000-0003-1476-6253

Elias José de Lima Júnior ${ }^{2}$ http://orcid.org/0000-0003-3566-8679

Simone Alves Pedersen ${ }^{3}$ http://orcid.org/0000-0003-3119-9801

RESUMO: A Base Nacional Curricular Comum (2017) inovou ao considerar a saúde socioemocional além da biológica, o que dialoga com o modelo das Escolas Promotoras de Saúde. Todavia, no desenvolvimento do texto, a BNCC enfatiza a saúde física e a discussão sobre as condutas que provocam impactos prejudiciais ao meio ambiente e saneamento básico, na dimensão coletiva, desconsiderando a importância da saúde mental e emocional no contexto educativo. A Pandemia do coronavírus em 2020 evidenciou a importância da educação em saúde, no âmbito individual e coletivo, assim como a relevância da saúde mental no enfrentamento dos novos desafios emergentes. Ainda, o retorno às aulas, diferentemente de outros períodos de férias, após os alunos terem passado por um período de isolamento, talvez sofrido a perda de familiares e/ou amigos, é um cenário de grande desafio, no qual a saúde física e emocional de todos os atores da educação será central, ressaltando a necessidade de uma educação em e para a saúde física e emocional. As leis e diretrizes nacionais, no campo da educação, precisam trazer meios para a construção de competências socioemocionais dos alunos, para que estejam preparados para enfrentar os desafios da escola e da vida.

PALAVRAS-CHAVE: Saúde, Competências socioemocionais, Base Nacional Comum Curricular, Escola Promotora de Saúde.

\section{HEALTH EDUCATION AND BNCC IN PANDEMIC TIMES}

ABSTRACT: The Common National Curricular Base (2017) innovated when considering

1 Doutor - Professor do Departamento de Educação da UNESP-Rio Claro, SP, Brasil. robertoiaochite@ gmail.com

2 Mestre em Educação - Doutorando em Educação da UNESP-Rio Claro, SP, Brasil. ver.eliaslima@gmail.com 3Mestre em Educação - Doutoranda em Educação da UNESP-Rio Claro, SP, Brasil. simonealvespedersen@ gmail.com

Rev. Fac. Educ. (Univ. do Estado de Mato Grosso), Vol. 35, Ano 20, № 1, p. 15-33, jan/jun, 2021. 
socioemotional health in addition to biological health, which dialogues with the Health Promoting Schools model. However, in the development of the text, the BNCC emphasizes physical health and the discussion about the behaviors that cause harmful impacts to the environment and basic sanitation, in the collective dimension, disregarding the importance of mental and emotional health in the educational context. The coronavirus pandemic in 2020 highlighted the importance of health education, at the individual and collective levels, as well as the relevance of mental health in facing new emerging challenges. Still, returning to school, unlike other vacation periods, after students have gone through a period of isolation, perhaps suffering the loss of family and/or friends, is a scenario of great challenge, in which physical and emotional health of all education actors will be central, stressing the need for education in and for physical and emotional health. National laws and guidelines, in the field of education, need to provide means for the construction of students' socio-emotional skills, so that they are prepared to face the challenges of school and life.

KEYWORDS: Health, Socioemotional learning, National Curricular Common Base, Health Promotion School.

\section{EDUCACIÓN EN SALUD Y BNCC EN TIEMPOS PANDÉMICOS}

RESUMEN: La Base Curricular Nacional Común (2017) innovó al considerar la salud socioemocional además de la salud biológica, que dialoga con el modelo de Escuelas Promotoras de la Salud. Sin embargo, en el desarrollo del texto, el BNCC enfatiza la salud física y la discusión sobre los comportamientos que causan impactos nocivos para el medio ambiente y el saneamiento básico, en la dimensión colectiva, sin tener en cuenta la importancia de la salud mental y emocional en el contexto educativo. La pandemia de coronavirus en 2020 destacó la importancia de la educación para la salud, a nivel individual y colectivo, así como la relevancia de la salud mental para enfrentar los nuevos desafíos emergentes. Aún así, regresar a la escuela, a diferencia de otros períodos de vacaciones, después de que los estudiantes hayan pasado por un período de aislamiento, tal vez sufriendo la pérdida de familiares y/o amigos, es un escenario de gran desafío, en el que la salud física y emocional de todos los actores de la educación será central, destacando la necesidad de educación en y para la salud física y emocional. Las leyes y directrices nacionales, en el campo de la educación, deben proporcionar medios para la construcción de habilidades socioemocionales de los estudiantes, de modo que estén preparados para enfrentar los desafíos de la escuela y la vida.

PALABRAS CLAVE: salud. Competencias socioemocionales, Base Curricular Común Nacional, Escuela de Promoción de la Salud. 


\section{INTRODUÇÃO}

A saúde é um dos temas mais relevantes da sociedade contemporânea, por ser essencial na qualidade de vida de todo ser humano e afetar diretamente o comportamento e as relações sociais. No ano de 2020 , a pandemia do covid-19 causou uma mudança de paradigma, evidenciando a necessidade da educação em saúde, não apenas física como a mental, e a importância do comportamento social responsável. Por esse motivo, a abrangência das políticas públicas de saúde oferecidas pelas instituições governamentais é constantemente questionada. A pesquisa realizada pelo Conselho Federal de Medicina (CFM), divulgada em 2018, apontou que $89 \%$ dos brasileiros classificam a saúde pública ou privada como péssima, ruim ou regular. Esse posicionamento é de 94\% dos que têm plano de saúde e de $87 \%$ dos que utilizam o Sistema Único de Saúde (SUS) (LABOISSIÈRE, 2018). Segundo Saldivas e Veras (2018), atualmente o Brasil investe em saúde cerca de $8 \%$ do PIB (Produto Interno Bruto), mas para atender a demanda crescente é necessário, além da melhoria da gestão, uma ampliação significativa dos recursos alocados.

Segundo Bandura (2004), as políticas públicas que focam exclusivamente na disponibilidade de atendimento médico à população não poderão ser sustentadas por muito tempo. Além das pessoas terem vidas mais longas e os recursos governamentais serem cada vez mais limitados, a qualidade da saúde dos indivíduos é influenciada significativamente pelos seus hábitos e estilo de vida. Portanto, o autor (BANDURA, 2004) afirma que para se promover saúde, além do oferecimento de serviços médicos a população, é necessário investir em educação para que as pessoas se percebam capazes de gerenciar a própria saúde de forma preventiva.

A relação entre saúde e educação não é uma abordagem recente no cenário nacional e internacional. Os primeiros documentos relacionados a esse tema foram elaborados no final do sec. XVIII. Figueiredo et al. (2010), em um resgate histórico sobre a saúde na escola, informam que a interação entre saúde e educação começou com o médico alemão Johann Peter Frank (1745-1821), considerado o pai da saúde escolar por ter publicado o primeiro guia sobre esse tema, em 1779.

No contexto brasileiro, Souza e Jacobina (2009) afirmam que a relação entre saúde e educação passou por três fases. A primeira foi a fase higienista, entre o final do século XIX e início do século XX, caracterizada pelo foco no aspecto biológico da doença, por meio de uma educação voltada para ensinar hábitos de higiene. A segunda, denominada de fase sanitarista, a partir de 
meados do século $X X$, teve como objetivo - além de ensinar hábitos de higiene - desenvolver nos alunos a necessidade de cooperarem com as campanhas profiláticas. A fase atual, nomeada de "Educação em Saúde", surgiu na segunda metade do século XX e apresenta uma visão global entre saúde e educação, enfatizando, além da prevenção de diversas doenças, a necessidade de ensinar hábitos saudáveis aos educandos.

Nessa perspectiva, Barbi e Neto (2017) afirmam que a saúde de fato se tornou obrigatória nos currículos escolares do Brasil por meio da lei federal 5.692/71. Mohr e Schall (1992) argumentam que o objetivo estabelecido por esta lei era estimular o conhecimento, e a prática de hábitos de saúde básica e higiene deveria priorizar ações práticas e não explanações, conforme o parecer 2.264/74 do Conselho Federal de Educação. Gouvea (2003) explicita que esse programa, que incialmente foi implementado como uma disciplina específica, acabou por ser integrado na disciplina de Ciências, na década de 80. -

Essa fase foi influenciada pela Primeira Conferência Internacional sobre Promoção da Saúde, organizada pela Organização Mundial de Saúde (OMS), em Ottawa, Canadá, em novembro de 1986. Segundo laochite (2017), a Carta de Ottawa, elaborada nessa conferência, ampliou o conceito de promoção de saúde de uma perspectiva higienista-assistencialista para uma abordagem mais integral, coletiva, ambiental e interdisciplinar. Nessa visão, a saúde envolve necessariamente a tomada de decisões por parte do indivíduo, que se responsabiliza pela sua própria saúde, como também a da sociedade em que está inserido, assumindo a corresponsabilidade pela promoção da saúde a nível individual e coletivo, o que tem ficado claro com a pandemia do coronavírus de 2020.

Considerando essa perspectiva abrangente de educação em saúde, esse artigo tem como objetivo analisar como a Base Nacional Curricular Comum (BNCC), promulgada em dezembro de 2017, dialoga com o modelo das Escolas Promotoras de Saúde, que segundo a Organização Pan-Americana de Saúde (OPAS) atende os pré-requisitos de uma educação em saúde integral preconizada na Carta de Otawa. Para realizar essa investigação, adotamos a metodologia do ensaio teórico, que consiste em "um importante recurso para ampliar a interdisciplinaridade e promover a construção de saberes por meio da relação intersubjetiva ", conforme Meneghetti (2011, p.331) e, segundo Severino (2002, p. 153) é "uma exposição lógica e reflexiva em argumentação rigorosa de alto nível de interpretação e julgamento pessoal". 


\section{MODELO DAS ESCOLAS PROMOTORAS DE SAÚDE (EPS)}

A OMS e a OPAS, com base na Carta de Otawa, incentivam entre todos os países da América Latina e Caribe, a difusão e implantação do modelo Escolas Promotoras de Saúde (EPS), definida como uma estratégia integral e integradora para o fornecimento de serviços de saúde escolar que transcende a atenção médica tradicional e se fundamenta em ações de promoção da saúde no âmbito escolar, envolvendo a construção de conhecimentos, valores, aptidões, destrezas e práticas necessárias para a vida saudável. Na concepção da EPS, os educandos são sujeitos capazes de influenciar mudanças em benefício da saúde própria e de suas comunidades (OPAS/OMS BRASIL, 2018). Em conformidade com esse pensamento, Gomes (2009) argumenta que "uma escola promotora de saúde pode ser caracterizada como uma escola que procura constantemente um estilo de vida, de aprendizagem e de trabalho propício ao desenvolvimento da saúde." (GOMES, 2009, p.87).

A implantação do modelo de Escola Promotora de Saúde recomendado pela OPAS/OMS envolve três componentes: 1) Educação para a saúde com um enfoque integral, baseada nas necessidades dos alunos e de acordo com suas características individuais; 2) Criação de ambientes e entornos saudáveis com espaços físicos adequados e ambientes psicossociais sadios; e 3) Serviços de saúde e alimentação que buscam detectar e prevenir problemas de saúde e formar condutas de autocontrole associadas a fatores de risco (OPAS/OMS BRASIL, 2018).

No Brasil, houve experiências positivas de Escolas Promotoras de Saúde (BRASIL, 2007), em diversos estados brasileiros, com vários projetos como alimentação escolar, cultura de paz, redução da violência, saúde sexual e reprodutiva, entre outros. Segundo documento produzido, pelo Ministério da Saúde em parceria com o Ministério da Educação, as iniciativas dessas experiências começaram com professores e alunos, para a seguir envolver gestores, funcionários, famílias e comunidade, e finalmente se consolidar em programas curriculares. Essas ações foram realizadas por meio de políticas intersetoriais envolvendo conjuntamente os setores de saúde e educação. Entretanto, apesar das experiências bem-sucedidas acumuladas e da inovação dos programas, essas ações ocorreram de forma isolada, sem integração e sem potencializar as várias intervenções realizadas de forma mais abrangente (BRASIL, 2007).

Para atender a necessidade de se estabelecer diretrizes para uma Política Nacional de Educação em Saúde na Escola, os Ministérios da Saúde e da Educação assinaram as Portarias Interministeriais n.ำ 749/05 e n.ำ 1.820/06, 
e instituíram por meio do decreto presidencial no 6.286 , de 5 de dezembro de 2007, o Programa Saúde na Escola (PSE). Esse programa de nível nacional tem como pré-requisito básico a necessidade de adesão das secretarias municipais de saúde e educação e, consequentemente, a indicação das escolas da sua área de abrangência que participarão das suas ações (BRASIL, 2017).

Uma vez preenchidos esses critérios, a implementação do PSE nas escolas demanda a necessidade de articulação entre as equipes municipais da atenção básica em saúde e as equipes das escolas para o desenvolvimento de suas ações de planejamento, execução e monitoramento de condutas de prevenção, promoção e avaliação das condições de saúde dos alunos. $\mathrm{Na}$ avaliação das condições de saúde deveriam ser analisadas a saúde nutricional, ocular, bucal, auditiva, clínica (situação vacinal e doenças) e psicossocial dos alunos. Na promoção da saúde e prevenção de doenças e agravos deveriam ser realizadas ações direcionadas a alimentação saudável, prática corporal, saúde sexual e reprodutiva, prevenção ao uso de drogas, cultura de paz, saúde mental, saúde ambiental e desenvolvimento sustentável (BRASIL, 2007; 2009; 2017).

Não obstante as propostas de intervenção do PSE indicarem a adoção do modelo da Escolas Promotoras de Saúde como referência, e consequentemente ser um projeto intersetorial entre saúde e educação, o contexto do documento aponta que a ênfase maior das ações recai sobre o setor de saúde, sendo pouco desenvolvido por iniciativa da escola. No caderno sobre saúde na escola com orientações sobre o PSE, publicado pelo Ministério da Saúde (BRASIL, 2009), pode-se verificar as atribuições dos médicos, enfermeiros, dentistas e outros profissionais de saúde no desenvolvimento do programa, mas não dos profissionais relacionados a educação (professores, gestores, funcionários), alunos, família e comunidade, sugerindo nesse contexto que esses atores não sejam protagonistas, mas meros coadjuvantes e/ou alvos das ações do PSE. Segundo laochite (2017), o modelo das Escolas Promotoras de Saúde envolve ações interdisciplinares com processos de ensino que valorizem as dimensões cognitiva, afetiva, social e motora tanto nas dimensões individuais como coletivas, e fica, por conseguinte, evidente a necessidade de um movimento de todos os agentes da comunidade escolar (alunos, professores, pais, gestores e funcionários).

Pode-se observar uma outra limitação com a Portaria № 1.055, de 25/04/2017, que estabeleceu um prazo de 24 (vinte e quatro) meses para o desenvolvimento do PSE, sugerindo que esse programa não é uma ação permanente de educação em saúde para as escolas que aderiram ao projeto. Além dessas limitações, os critérios para adesão ao PSE fizeram com que o mesmo 
ficasse restrito aos municípios e escolas que compactuaram com a proposta, não sendo, portanto, um programa que envolva todos os municípios, redes de ensino e escolas do Brasil.

Ao se comparar o relatório das experiências brasileiras das Escolas Promotoras de Saúde (EPS) divulgado em 2007 (BRASIL, 2007), com o Programa Saúde na Escola (PSE), detalhado no Cadernos de Atenção Básica sobre saúde na escola, que afirma se referenciar na EPS (BRASIL, 2009), observa-se nesses documentos, que enquanto o relatório da EPS de 2007 indica que as ações se iniciaram com o protagonismo de professores e alunos se expandindo para toda a comunidade escolar, o PSE se desenvolveu como um projeto dos profissionais da saúde para ser aplicado no contexto escolar. Conquanto as duas propostas afirmarem serem o resultado de uma política intersetorial entre o Ministério da Saúde e Educação, apenas o documento das experiências brasileiras da EPS de 2007 é assinado em conjunto pelos secretários da saúde e educação, enquanto o do PSE é subscrito somente pela Ministério da Saúde.

O modelo das Escolas Promotoras de Saúde (OPAS/OMS BRASIL, 2007), indicam a necessidade do protagonismo de todos os agentes da comunidade escolar e de saúde na implantação da proposta. Nessa perspectiva é fundamental que políticas públicas em parceria com os setores de saúde e educação desenvolvam projetos conjuntos. Na educação, as orientações da Base Nacional Comum Curricular são fundamentais no desenvolvimento da EPS como é defendida pela OPAS/OMS.

\section{BASE NACIONAL CURRICULAR COMUM}

Como documento oficial de implantação de políticas públicas relacionadas à educação no Brasil, a Base Nacional Comum Curricular (BNCC), homologada em 20 de dezembro de 2017, tem como objetivo fundamental assegurar uma formação básica comum para todos os brasileiros. Visando alcançar essa meta, a BNCC estabelece as competências e diretrizes que devem nortear os conteúdos mínimos dos currículos da Educação Infantil, Ensino Fundamental e Ensino Médio de todas as escolas do território brasileiro (BRASIL, 2017).

Para justificar a sua criação, a BNCC afirma que a elaboração do seu conteúdo atendeu ao artigo 210, da Constituição Brasileira de 1988, que estabeleceu a necessidade de serem "fixados conteúdos mínimos para o ensino fundamental, de maneira a assegurar formação básica comum e respeito aos valores culturais e artísticos, nacionais e regionais" (BRASIL, 1988), e, consequentemente o Artigo 26 da Lei de Diretrizes e Base da Educação Nacional N 
9394/96, que afirmou a obrigatoriedade dos currículos da Educação Infantil, Ensino Fundamental e Ensino Médio terem uma base nacional comum, a ser complementada, em cada sistema de ensino e em cada estabelecimento escolar, com uma parte diversificada, exigida pelas características regionais e locais da sociedade, da cultura, da economia e dos educandos (BRASIL, 1996). Acolheu a Lei Federal $N^{\circ} 13.0005 / 14$, que promulgou o Plano Nacional de Educação (PNE), o qual reafirma a demanda de:

[...] estabelecer e implantar, mediante pactuação interfederativa [União, Estados, Distrito Federal e Municípios], diretrizes pedagógicas para a educação básica e a base nacional comum dos currículos, com direitos e objetivos de aprendizagem e desenvolvimento dos(as) alunos(as) para cada ano do Ensino Fundamental e Médio, respeitadas as diversidades regional, estadual e local (BRASIL, 2014).

Em atendimento à essa legislação, a BNCC foi elaborada com a participação de diversos setores da sociedade civil e especialistas de várias áreas do conhecimento. Após três versões, foi homologada pelo Conselho Nacional de Educação em 20 de dezembro de 2017. Dessa forma, a BNCC é definida como "um documento de caráter normativo que define o conjunto orgânico e progressivo de aprendizagens essenciais que todos os alunos devem desenvolver ao longo da Educação Básica, de acordo com o que estabelece o Plano Nacional de Educação (PNE)" (BRASIL, 2017, p.7).

A BNCC, como política pública relacionada à educação, pode ser denominada de saberes curriculares. Segundo Tardif (2014, p.38), os saberes curriculares normalmente se apresentam "sob a forma de programas escolares (objetivos, conteúdos, métodos), que os professores devem aprender e aplicar". Para esse pesquisador, na atuação em sala de aula os docentes mobilizam além desses saberes, os saberes profissionais desenvolvidos no processo de formação, os saberes disciplinares relacionados a área do conhecimento que lecionam, e os saberes da experiência profissional desenvolvidos no decorrer dos anos no exercício da prática docente. Os saberes curriculares estabelecidos pela BNCC não são os únicos saberes que os professores mobilizam em sala de aula, todavia, eles exercem um papel significativo no processo de ensino-aprendizagem.

Nessa perspectiva, a BNCC apresenta logo no início do documento um conjunto de 10 competências gerais que devem assegurar as aprendizagens essenciais que consubstanciam, no âmbito pedagógico, os direitos de 
aprendizagem e desenvolvimento dos educandos durante toda a educação básica (BRASIL, 2017).

No que se refere a saúde, a BNCC defende uma educação em saúde de forma ampliada, integrando diversos fatores de uma vida saudável, por meio dos seguintes termos descritos na competência geral 8: "Conhecer-se, apreciar-se e cuidar de sua saúde física e emocional, reconhecendo suas emoções e as dos outros, com autocrítica e capacidade para lidar com elas e com a pressão do grupo." (BRASIL, 2017, p.19). Por essa formulação, pode-se perceber que a promoção da saúde no contexto escolar deve envolver aspectos físicos e emocionais, tanto no caráter pessoal como no das relações interpessoais. Essa ênfase na promoção de uma saúde integral, descrita na competência 8, pode ser verificada na correlação dessa competência com as outras competências gerais, nas quais se observa a importância da promoção de habilidades intrapessoais e interpessoais de forma transversal, descritas como a necessidade de: a) "Valorizar e utilizar os conhecimentos historicamente construídos ... colaborando para a construção de uma sociedade solidária" (Competência 1); b) "Utilizar conhecimento das linguagens ... para expressar-se e partilhar informações, experiências, ideias e sentimentos em diferentes contextos e, com eles, produzir sentidos que levem ao entendimento mútuo." (Competência 4); c) "Valorizar a diversidade de saberes e vivências..." (Competência 6); d) "Argumentar com base em fatos, dados e informações confiáveis, para formular, negociar e defender ideias, pontos de vista e decisões comuns que respeitem e promovam os direitos humanos ..." (Competência 7); e) "Exercitar a empatia, o diálogo, a resolução de conflitos e a cooperação, fazendo-se respeitar e promovendo o respeito ao outro e aos direitos humanos" (Competência 9); f) "Agir pessoal e coletivamente com autonomia ... tomando decisões, com base nos conhecimentos construídos na escola, segundo princípios éticos democráticos, inclusivos, sustentáveis e solidários." (Competência 10) (BRASIL, 2017, p.18 e 19).

Considerando que a BNCC deve nortear os conteúdos mínimos dos currículos, no que se refere a educação em saúde é importante analisar se a mesma atende a proposta do modelo das Escolas Promotoras de Saúde defendida pela OPAS/OMS, das quais o Brasil é membro.

\section{A PROMOÇÃO DAS ESCOLAS PROMOTORAS DE SAÚDE NA BNCC}

Considerando a ênfase em uma educação em saúde de forma integral nas competências gerais da BNCC, como defende o modelo das Escolas 
Promotoras de Saúde, é importante analisar como esse propósito é efetivado no contexto desse documento. Tomando como princípio básico que as competências gerais da BNCC devem se inter-relacionar e se desdobrar na construção de conhecimentos, desenvolvimento de habilidades e formação de atitudes e valores (BRASIL, 2017), essa abordagem de uma saúde integral deve consequentemente estar integrada nas diversas áreas de conhecimento. Para verificar essa integração optou-se em analisar a frequência em que o termo saúde é citado na BNCC nas diferentes disciplinas e habilidades, conforme demonstrado no Quadro 1.

Quadro 1 - Frequência do termo saúde na BNCC

\begin{tabular}{|c|c|c|c|c|c|c|c|}
\hline \multirow[b]{2}{*}{ Total } & \multirow[b]{2}{*}{ Introdução } & \multirow{2}{*}{$\begin{array}{c}\text { Educação } \\
\text { Infantil }\end{array}$} & \multicolumn{5}{|c|}{ Ensino Fundamental } \\
\hline & & & $\begin{array}{l}\text { Ed. } \\
\text { Física }\end{array}$ & Matemática & Ciências & Geografia & $\begin{array}{l}\text { Ens. } \\
\text { Relig. }\end{array}$ \\
\hline 44 & 03 & 01 & 11 & 01 & 24 & 01 & 03 \\
\hline
\end{tabular}

Na introdução, o termo saúde é indicado na competência geral 8, como uma necessidade de conhecer, apreciar e cuidar da saúde de forma integral, envolvendo as dimensões físicas e emocionais, de forma intra e interpessoal. Nessa parte do documento, a saúde é apontada também como um dos temas contemporâneos que devem ser incorporados aos currículos de forma transversal e integradora em atendimento ao Parecer CNE/CEB no 11/2010 e Resolução CNE/CEB no 7/2010). É importante considerar que nesses dois documentos a saúde é abordada como um direito que deve ser promovido em articulação com outras políticas públicas.

O termo saúde na Educação Infantil é sinalizado apenas uma vez no eixo corpo, gestos e movimentos, como uma necessidade de os alunos reconhecerem a importância do cuidado com a própria saúde e a manutenção de ambientes saudáveis.

Com relação à Educação Física, a saúde é citada como uma prática corporal, que no contexto de um produto cultural, deve promover de forma autônoma o cuidado com o corpo e a própria saúde. Para atingir esse objetivo é indicado a promoção das competências de o aluno refletir criticamente sobre os processos de saúde/doença, identificar os modelos de saúde vinculados na mídia para discutir suas posturas consumistas e preconceituosas, e usufruir das práticas corporais para ampliar as redes de sociabilidade e a promoção da saúde. Para desenvolver essas competências são apontadas três habilidades: 1) 
Construir coletivamente normas de convívio que viabilizem a participação de todos na prática de exercícios físicos; 2) Discutir as transformações históricas dos padrões de saúde apresentados nos meios de comunicação; e 3) Identificar as diferenças e semelhanças entre a ginástica de conscientização corporal e as de condicionamento físico e consequentemente discutir como elas podem contribuir para a melhoria das condições de vida, saúde, bem-estar e cuidado consigo mesmo.

Na área de Ciências da Natureza, a saúde é apontada na competência específica 8, como uma demanda de agir pessoal e coletivamente com base nos conhecimentos das Ciências da Natureza, para tomar decisões sobre a saúde individual e coletiva, tendo como referência princípios éticos, democráticos, sustentáveis e solidários. Nessa perspectiva, as três unidades temáticas de ciências da natureza (Matéria e Energia; Vida e Evolução; e Terra e Universo), devem se articular para promover uma educação em saúde em que o aluno deve assumir "o protagonismo na escolha de posicionamentos que representem autocuidado com seu corpo e respeito com o corpo do outro, na perspectiva do cuidado integral à saúde física, mental, sexual e reprodutiva" (BRASIL, 2017, p.325). Além desse objetivo, é indicado que o aluno compreenda que a saúde deve envolver também "pensar em saneamento básico, geração de energia, impactos ambientais, além da ideia de que medicamentos são substâncias sintéticas que atuam no funcionamento do organismo." (BRASIL, 2017, p.327).

Esses princípios de saúde na área de ciências se expressam nas habilidades do Ensino Fundamental Anos Iniciais (1ㅇa ao 5 Ano), ao discutir as razões dos hábitos de higiene e de manutenção da saúde auditiva e visual. Por último, no Ensino Fundamental Anos Finais (6ㅇa 9o Ano), as habilidades são direcionadas para organizar um cardápio equilibrado, analisar as políticas públicas de saúde com base na comparação de indicadores, e argumentar sobre a importância da vacinação na saúde pública. (BRASIL, 2017).

Nas demais áreas o termo saúde é citado como um pano de fundo para outros conhecimentos. Em Matemática, a saúde é apresentada como um dos contextos para interpretar dados estatísticos. Em Geografia para identificar a presença ou ausência de serviços públicos essenciais como transporte, segurança, saúde e educação, enquanto no Ensino Religioso o propósito é o de analisar a influência das tradições religiosas nesse tema.

Esses dados indicam que o tema educação em saúde é incialmente abordado de uma forma integral nas competências gerais da BNCC, e a frequência com que esse tema é citado e como ele é tratado no contexto do documento, sugere uma contradição entre as competências gerais e a sua 
implementação nas diversas áreas do conhecimento.

Apesar de a BNCC apontar inicialmente nas competências gerais que a saúde possui uma dimensão transversal que deve ser trabalhada em todas as disciplinas, as áreas de Ciências da Natureza e Educação Física são as mais enfatizadas. Não obstante ser indicado nas competências gerais que a promoção da saúde deve envolver aspectos físicos e emocionais, intra e interpessoais, o contexto do documento destaca uma educação em saúde com foco higienista e biologizante, na dimensão individual, e, na dimensão coletiva a ênfase é dada nas condutas que provocam impactos prejudiciais ao meio ambiente e saneamento básico.

Essa contradição também pode ser observada no Parâmetro Curricular Nacional (PCN), sobre saúde, promulgado em 1998. Nesse documento é indicada a necessidade de se aplicar o conceito de "Cidade Saudável", especificado em uma reunião da OMS, no Canadá, na década de 80. Nessa perspectiva, a promoção da saúde ocorre quando são asseguradas as condições de vida digna a todos os cidadãos, e, especificamente, por meio da educação e a adoção de estilos de vida saudáveis. Estabeleceu-se no PCN, que as escolas que promovem saúde devem ter uma visão integrada que envolva todos os aspectos da escola, para promover desta forma um ambiente saudável que favoreça a aprendizagem, com base em um modelo de saúde que inclui a interação dos aspectos físicos, psíquicos, socioculturais e ambientais, com a participação ativa de todos os envolvidos (BRASIL, 1998). Apesar desse bojo mais amplo sobre educação e saúde, Barbi e Neto (2017), afirmam que o PCN mantém e supervaloriza as características biologizantes da saúde em detrimento da saúde como resultado do bem-estar psicossocial do aluno.

Além dessas considerações apresentadas, apesar de inicialmente a BNCC apresentar uma proposta de educação em saúde de forma integral, em consonância com o modelo das Escolas Promotoras de Saúde, no contexto do documento não há nenhuma referência à Organização Mundial de Saúde (OMS), à Organização Pan-Americana de Saúde (OPAS), às Escolas Promotoras de Saúde (EPS), ao Programa Saúde na Escola (PSE) ou qualquer outra ação intersetorial entre o Ministério de Saúde (MS) e Educação (MEC) para a promoção da saúde na escola. Essa constatação pode ser verificada também ao se analisar os documentos básicos de referência da BNCC, a Lei de Diretrizes e Base da Educação Nacional N 9394/96 e o Plano Nacional de Educação (PNE), Lei Federal N 13.0005/14. Entretanto, a própria BNCC afirma que para se promover a saúde individual e coletiva é necessária uma integração com as diversas políticas públicas (BRASIL, 2017). 
Essa análise da BNCC indica a necessidade de uma articulação maior entre o Ministério de Educação e Saúde na promoção da saúde escolar. $O$ Ministério da Saúde não pode considerar professores, alunos, gestores e funcionários da escola, bem como as famílias e a comunidade em geral como meros receptores de suas ações relacionadas a saúde, como é apresentado nos documentos do Programa Saúde na Escola (BRASIL, 2007, 2009, 2017). Da mesma forma, o Ministério da Educação precisa de uma articulação com a saúde por meio da implantação de uma política pública intersetorial efetiva para a promoção de uma saúde integral.

A OPAS/OMS argumenta que o modelo das Escolas Promotoras de Saúde (EPS) atende essa demanda de articulação entre os diversos setores na promoção da saúde escolar, por ser uma estratégia integral e integradora para o fornecimento de serviços de saúde escolar que transcende a atenção médica tradicional e se fundamenta em ações de promoção da saúde no âmbito escolar (OPAS/OMS BRASIL, 2018).

\section{CONSIDERAÇÕES FINAIS}

Na escola, as crianças encontram uma possibilidade para aprendizagem de diferentes formas de comportamentos, o que nem sempre acontece no âmbito familiar. Bandura (2004) afirma que "muitos dos hábitos ao longo da vida que colocam em perigo a saúde são formados na infância e adolescência" (BANDURA, 2004, p. 15). O autor complementa que os hábitos saudáveis podem ser aprendidos pelas práticas familiares, entretanto, as escolas têm um papel importante na promoção da saúde de uma nação, por ser o lócus privilegiado para a promoção de hábitos saudáveis e formação de habilidades autorregulatórias. Infelizmente, a realidade tem demonstrado que a maioria das escolas não estão aparelhadas adequadamente com os recursos necessários, treinamento, e incentivos para preconizarem a promoção da saúde física e mental desde a Educação Infantil.

O modelo de Escolas Promotoras de Saúde (EPS), preconizado pela OPAS/OMS, implica a necessidade da participação de toda a comunidade escolar (professores, alunos, gestores, funcionários e família, entre outros) em sintonia com os serviços públicos de saúde, não como meros expectadores, mas como agentes de sua própria promoção de uma vida saudável. Bandura (1999, p. 42) diz que "atualmente, se reconhece amplamente que a saúde das pessoas está parcialmente em suas mãos". O homem, como ser agêntico, pode controlar boa parte de sua vida, seus hábitos, seu comportamento, e assim, influenciar diretamente na sua saúde física e mental. 
De acordo com a teoria social cognitiva (BANDURA, 1986), o homem por meio da sua capacidade agêntica pode exercer parcialmente uma influência intencional sobre o próprio comportamento e o contexto social em que vive, estabelecendo planos de ação para alcançar determinados objetivos, antecipando as consequências das suas ações para evitar resultados indesejados e guiando a própria conduta por meio do processo de autorregulação, definido como: "um mecanismo interno consciente e voluntário de controle, que governa o comportamento, os pensamentos e os sentimentos pessoais, tendo como referência metas e padrões pessoais de conduta, a partir dos quais se estabelece consequência para o mesmo" (POLYDORO; AZZI, 2008, p.151).

Entretanto, as pessoas dificilmente se engajarão em ações, como promover a própria saúde e de outros, se não se julgarem capazes para isso. Bandura afirma que "apesar de outros fatores poderem servir de guias e motivadores, eles estão enraizados na crença central do quanto uma pessoa se julga capaz para produzir as mudanças desejadas como resultado de suas ações" (BANDURA, 2004, p. 114), ao se referir às crenças de autoeficácia, que o autor define como "as crenças do indivíduo em sua capacidade em organizar e executar cursos de ação requeridos para produzir certas realizações" (BANDURA, 1997, p.3).

Pessoas com autoeficácia robusta enxergam as dificuldades como transponíveis, enquanto pessoas com autoeficácia fraca encaram as dificuldades como instransponíveis. Como afirmou Bandura "hábitos relacionados à saúde não mudam por um simples ato de vontade. É necessário ter uma crença de autoeficácia motivadora e habilidades autorregulatórias" (BANDURA, 2004, p. 9; BANDURA, 2005, p. 246).

Pela teoria sociocognitiva (Bandura, 2004), para um programa ser efetivo na prevenção de hábitos não saudáveis, são necessários quatro componentes: 1) informação, 2) desenvolvimento de habilidades de gerenciamento pessoal (autorregulação) e social para hábitos saudáveis, 3)fortalecimento da crença de autoeficácia para as pessoas tornarem-se resilientes e exercerem o controle perante as dificuldades e retrocessos que surgem inevitavelmente, e 4) criação de suporte social para as mudanças estabelecidas (BANDURA, 2004).

Nessa abordagem teórica, não basta criar programas que se limitem a oferecer informações sobre saúde aos educandos. São necessárias ações pedagógicas que ensinem as pessoas como se autorregularem para a promoção da saúde e que possibilitem o fortalecimento de sua crença de autoeficácia sobre essa temática, além de oferecer uma estrutura com apoio social que as ajudem a superar os desafios que surgem no processo.

A Organização Pan-Americana da Saúde/Organização Mundial da 
Saúde (2016) afirma que "são muitos os fatores sociais que podem contribuir para a falta de saúde, entre eles: rápidas mudanças sociais, condições de trabalho estressantes, discriminação de gênero, exclusão social, estilo de vida não saudável, violência e violação dos direitos humanos" (OPAS/OMS, 2016, $\mathrm{s} / \mathrm{p})$, problemas esses que fazem parte do cotidiano escolar. Entre eles cita o processo avaliativo em que a escola é submetida para se verificar o nível de atendimento do currículo oficial estabelecido. Bandura (2004) reflete que, como em outros sistemas sociais, a escola foca nas áreas em que é avaliada. Como os sistemas educacionais a partir da homologação da BNCC serão avaliados tendo como base esse documento, é de fundamental importância que a educação em saúde integral expressa nas competências gerais da BNCC esteja plenamente articulada nas diversas áreas de conhecimento e habilidades a serem desenvolvidas nos educandos.

Os estudos apresentados nesse artigo reconhecem a relevância da Base Nacional Curricular Comum (BNCC) e das Escolas Promotoras de Saúde (EPS) no Brasil. Isso posto, apontam a necessidade de uma articulação maior entre o Ministério de Educação e o Ministério da Saúde, na promoção de uma educação em saúde como preconizada pela OPAS/OMS, isto é, focada na EPS, com uma proposta de saúde integral envolvendo aspectos físicos e emocionais, tanto a nível pessoal com interpessoal, que sejam contemplados na BNCC, e que valorizem o protagonismo de todos os atores da comunidade escolar.

A pandemia do covid-19 transformou a vida do homem a nível global. A sua rápida disseminação não permitiu que programas preventivos fossem instaurados. O alerta, todavia, foi dado. A Educação em Saúde é urgente, não apenas no que se refere aos cuidados físicos, mas também precisamos ter hábitos que promovam a saúde mental, sem dualismos. Desde aprender a lavar as mãos corretamente, até respeitar o próximo, ter empatia e consciência de coletividade são comportamentos fundamentais para superar desafios de (sobre)vivência em sociedade.

Esse artigo aponta também para a demanda de ampliar os estudos na área de educação em saúde emocional e interpessoal, ao lado de uma efetiva formação dos profissionais envolvidos, para que alarguem seu entendimento de saúde além dos aspectos biológicos, e que se sintam capazes de lidar com os problemas que enfrentam no cotidiano escolar. Enquanto os gestores e professores não se sentirem capazes de promover saúde na escola, por meio de conhecimentos e fortalecimento de suas crenças de autoeficácia, dificilmente terão motivação para se envolverem em iniciativas que possam transformar a realidade escolar e promover a saúde nos educandos. 


\section{REFERÊNCIAS}

BANDURA, Albert. Social Foundations of thought and action: a social cognitive theory. Englewood Cliffs, NJ: Prentice Hall, 1986.

BANDURA, Albert. Self-efficacy: the exercise of control. New York, NY: Freeman, 1997.

BANDURA, Albert. Health promotion from the perspective of social cognitive theory. Psychology and health, v. 13, n.4, p.623-649, 1998.

BANDURA, Albert. Health promotion by social cognitive means. Health education \& behavior, v. 31, n. 2, p. 143-164, 2004.

BANDURA, Albert. The primacy of Self-Regulation in Health Promotion. Applied Psychology: na International review, 54 (2), p. 245-254, 2005.

BANDURA, Albert. Ejercicio dela eficacia personal y coletiva em sociedades cambiantes. In: Auto-Eficacia: Cómo afrontamos los câmbios de la Sociedad actual. Bandura, A. (Ed.). Desclée De Brouwer, Biblioteca de Psicología, p. 1955, Espanha, 1999.

BARBI, Juliana Silva Pedro; NETO, Jorge Megid. A Saúde nos anos finais do Ensino Fundamental: Uma análise de documentos de referência. XI Encontro Nacional de Pesquisa em Educação em Ciências - XI ENPEC Universidade Federal de Santa Catarina, Florianópolis, SC - 3 a 6 de julho, p.1-8, 2017.

BRASIL. Lei de Diretrizes e Bases da Educação Nacional - Lei no 5.692, de 11 de agosto de 1971.

BRASIL. Lei de Diretrizes e Bases da Educação Nacional - Lei no 9394/1996, de 20 de dezembro de 1996.

BRASIL. Parâmetros curriculares nacionais - Saúde. Secretaria de Educação Fundamental. - Brasília: MEC/SEF, 1998.

BRASIL. MINISTÉRIO DA SAÚDE. Escolas promotoras de saúde: experiências no Brasil. Ministério da Saúde, 2007.

BRASIL, Presidência da República - Casa Civil. Institui o Programa Saúde na Escola - PSE. Decreto no 6.286, de 5 de dezembro de 2007.

BRASIL. MINISTÉRIO DA SAÚDE. Saúde na Escola. Série B. Textos Básicos de Saúde. Cadernos de Atenção Básica, n. 24. Ministério da Saúde, 2009. 
BRASIL, Ministério da Educação. Base Nacional Comum Curricular. Terceira Versão. Brasília: Secretaria da Educação Básica, 2017.

BRASIL, Ministério da Saúde e Educação -Manual de Adesão ao Programa Saúde na Escola - PSE - 2017. Disponível em http://189.28.128.100/dab/ docs/portaldab/documentos/manual_adesao_pse_2017.pdf. Acesso em 02 de jun. de 2018.

BRASIL, Secretaria Nacional de Juventude. Coordenação Geral de Políticas Transversais. Participatório - Observatório Participativo da Juventude. Pesquisa Agenda Brasil: pesquisa nacional sobre o perfil e opinião dos jovens brasileiros -2013. Brasília: SNJ, 2013.

CARLINI-MARLATT, Beatriz. Jovens e drogas: saúde, política neoliberal e identidade jovem. Retratos da juventude brasileira: análises de uma pesquisa nacional, p. 303-321, 2005.

DAHLBERG, Linda. L.; KRUG, Etienne. G. Violência: um problema global de saúde pública. Ciênc. saúde coletiva [online]. 2006, vol.11, supl., pp.1163-1178. ISSN 1413-8123. http://dx.doi.org/10.1590/S1413-81232006000500007.

DE SOUZA, Isabela Pilar Moraes Alves; JACOBINAB, Ronaldo Ribeiro. Educação em saúde e suas versões na história brasileira. 2009.

FIGUEIREDO, Túlio A. M.; MACHADO, Vera Lúcia.; DE ABREU, Margaret S. A saúde na escola: um breve resgate histórico. Revista Ciência \& Saúde Coletiva, v. 15, n. 2, 2010.

GAUTHIER, Clermont. Por uma teoria da Pedagogia. Ijuí: Editora Unijui, 1998.

GOUVÊA, Lavn de. Educação para a saúde na legislação educacional no Brasil. Seminário Nacional Estado e Políticas Sociais no Brasil, 2003.

GOMES, José Precioso. As Escolas Promotoras de Saúde: uma via para promover a saúde e a educação para a saúde da comunidade escolar. Educação, v. 32, n. 1, 2009.

IAOCHITE, Roberto Tadeu. Investigações e Práticas em Escolas Promotoras de Saúde: aproximações com a Teoria Social Cognitiva. In: IAOCHITE, R. T.; AZZI, R. G. (Orgs) Autoeficácia em Contextos de Saúde, Educação e Política. Volume I. Coleção TSC em Debate. Porto Alegre - RS. Letra 1, 2017. 
IPPOLITO-SHEPHERD, Josefa. Promoção da saúde no âmbito escolar: a iniciativa regional Escolas Promotoras da Saúde. In: Escola promotora de saúde: manual. SBP, p. 5-11, 2005.

LABOISSIÈRE, Peter. Quase 90\% dos brasileiros consideram a saúde péssima, ruim ou regular. http://agenciabrasil.ebc.com.br/saude/noticia/2018-06/para-89-dos-brasileiros-saude-e-considerada-pessima-ruim-ou-regular. Acessado em: 30 out. 2018.

MENEGHETTI, Francis Kanashiro. O que é um ensaio-teórico? RAC-Revista de Administração Contemporânea, v. 15, n. 2, 2011.

MENIN, Maria Suzana de Stefano; BATAGLIA, Patrícia Unger Raphael; ZECHI, Juliana. Experiências bem-sucedidas de educação moral no Brasil. São Paulo: Cortês, 2013.

MOHR, Adriana; SCHALL, Virgínia T. Rumos da educação em saúde no Brasil e sua relação com a educação ambiental. Cadernos de Saúde Pública, v. 8, p. 199-203, 1992.

OPAS/OMS Brasil - Escolas Promotoras de Saúde - Disponível em (http://www. paho.org/bra/index.php?option=com_content\&view=article\&id=588:escolas-promotoras-de-saude\&Itemid=685. Acesso em 02 mai 2018.

OPAS/OMS BRASIL. OPAS/OMS apoia governos no objetivo de fortalecer e promover a saúde mental da população. Publicado em 10 de out de 2016. Disponível em: <https://www.paho.org/bra/index.php?option=com_content\&view=article\&id=5263:opas-oms-apoia-governos-no-objetivo-de-fortalecer-e-promover-a-saude-mental-da-populacao\&Itemid=839>. Acessado em 09 set 2018.

POLYDORO, Soely; AZZI, Roberta G. Auto-regulação: aspectos introdutórios. In: BANDURA, Albert.; AZZI, Roberta G.; POLYDORO, Soely. (Orgs.) Teoria Social Cognitiva - Conceitos Básicos. Porto Alegre: Artmed, p. 149-164. 2008.

SALDIVA, Paulo Hilário Nascimento; VERAS, Mariana. Gastos públicos com saúde: breve histórico, situação atual e perspectivas futuras. Estudos Avançados, v. 32, n. 92, p. 47-61, 2018.

SEVERINO, Antonio J. Metodologia do trabalho científico. 22.ed.rev e ampl. São Paulo: Cortez, 2002.

TARDIF, Maurice. Saberes docentes e formação profissional. Petrópolis, RJ: Vozes, 2014. 
TOGNETTA, Luciene Regina Paulino, DAUD, Rafael Petta. Formação docente e superação em bullying: um desafio para tornar a convivência ética na escola. Perspectiva - Revista do Centro de Ciências da educação, Volume 36, n.1, p. 369-384, jan./mar. 2018.

WHO - World Health Organization - Partners in Life Skills Education - Conclusions from a United Nations Inter-Agency Meeting. 1998.

Data de recebimento: 11.06 .2020

Data de aceite: 12.07.2021 